\section{The ripple effect: growing your practice}

As a dental practice owner, you may be taking the time to review where you are today and looking at ways, large or small, to optimise the success of your business, both now and in the future.

Having a good understanding of the financial aspects of running your practice will help towards improving profitability, which can be achieved in a number of simple yet effective ways. Benchmarking is one of these and provides a useful indication of practice performance within the current market, helping you to develop efficient growth plans.

Embarking on the acquisition route could be another option to consider. Making a business acquisition is a fast and effective way to grow your dental business. It can give you immediate cash flow, ready-made customers, assets, a new geographical location or reduce competition, and can minimise the risks and time associated with growing your practice organically.

Obtaining funding for your strategic

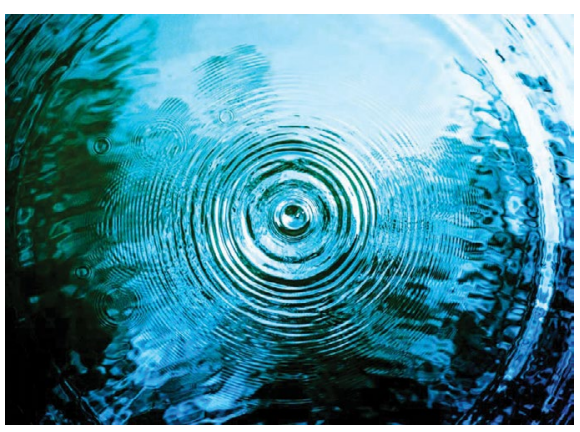

acquisition will be a key part of the process, so having a clear insight into the 'perfect practice' in the eyes of a lender will support your application preparation.

Hazlewoods Business Advisers and Chartered Accountants dental experts will be working with Lloyds Bank Healthcare specialists to help shine a light on some of these key areas for growing your dental business in a live webinar, Tuesday 5 October 2021, 6-7 pm. Find out more here: bit.ly/ hazlewoods-dental-webinar-21

www.hazlewoods.co.uk

\title{
Expanding the bone regeneration product line
}

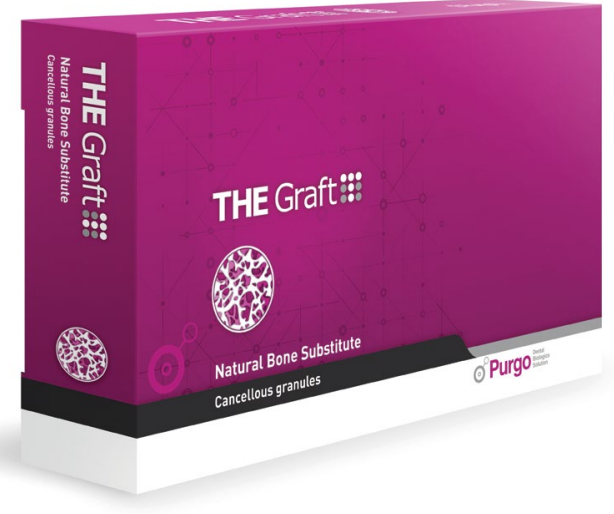

Neoss maintains its clear focus on innovation and has a continuous plan of new market-leading product solutions that will be presented over the next few years.

On 1 September, Neoss became a key partner and distributor of the Purgo Xenograft product range in the German, Swedish and United Kingdom markets. Neoss are very excited about working with the Purgo team.

The first product range, 'THE Graft', is a natural porous bone matrix that likens

the physical and chemical aspects of the mineralised matrix of human bone. This exciting Xenograft product line will add new dimensions to Neoss' existing bone regeneration offering.

Founded in 2000 by a professor of prosthodontics and a specialist engineer, Neoss offers intelligent dental solutions that are intuitively simple to use. The company's products are designed to allow dental professionals to provide reliable and cost-effective treatments to their patients with excellent long-term results. Leading with innovation and integrity, Neoss develops smart treatment solutions and works closely with each practice to drive Intelligent Simplicity, making the complex less complicated. Headquartered in Harrogate, UK, with research and development based in Gothenburg, Sweden, the company has established a global footprint with long-standing presence in key markets. To find out more visit https://www.neoss.com.

To experience THE Graft first hand, contact your Neoss sales office or sales professional.
Smooth surface finish with a natural high sheen

Tokuyama are the only composite manufacturer to use patented spherical filler particles within their composite materials, each variant utilising spherical particles of different diameters to maximise their optical and physical properties for the desired indication.

In addition to optimised optical properties, resulting in enhanced aesthetic restorations, Tokuyama's spherical filler particles offer other significant advantages compared with the irregular-shaped filler particles used by all other manufacturers. Quicker and easier to pack into undercuts, reducing the risk of voids; easier to sculpt and carve, producing enhanced morphology of the final restoration; and a much smoother surface finish, which has a natural high sheen that requires minimal if any polishing.

Tokuyama's development of spherical filler particles has culminated in Omnichroma, the world's only colourless universal composite which matches every tooth colour no matter what the shade.

Tokuyama have extended the Omnichroma range with their new low-viscosity Omnichroma Flow, specifically for clinicians who prefer flowable materials for certain indications - anterior and posterior restorations, cavity bases or lining and composite/ceramic repairs. It offers the benefits of perfect colour matching whatever the shade, simplified inventory management, excellent cavity adaptation, non-sticky, excellent polishability, remarkable glossiness and freedom from BisGMA and bisphenol A-related monomers.

Only available from Trycare!

For more information about the complete Tokuyama range, including Omnichroma Flow, contact your local Trycare Representative, call 01274 885544 or visit www.trycare.co.uk. 